\title{
Low-cost Electromagnetic Heating Technology for Polymer Extrusion- based Additive Manufacturing
}

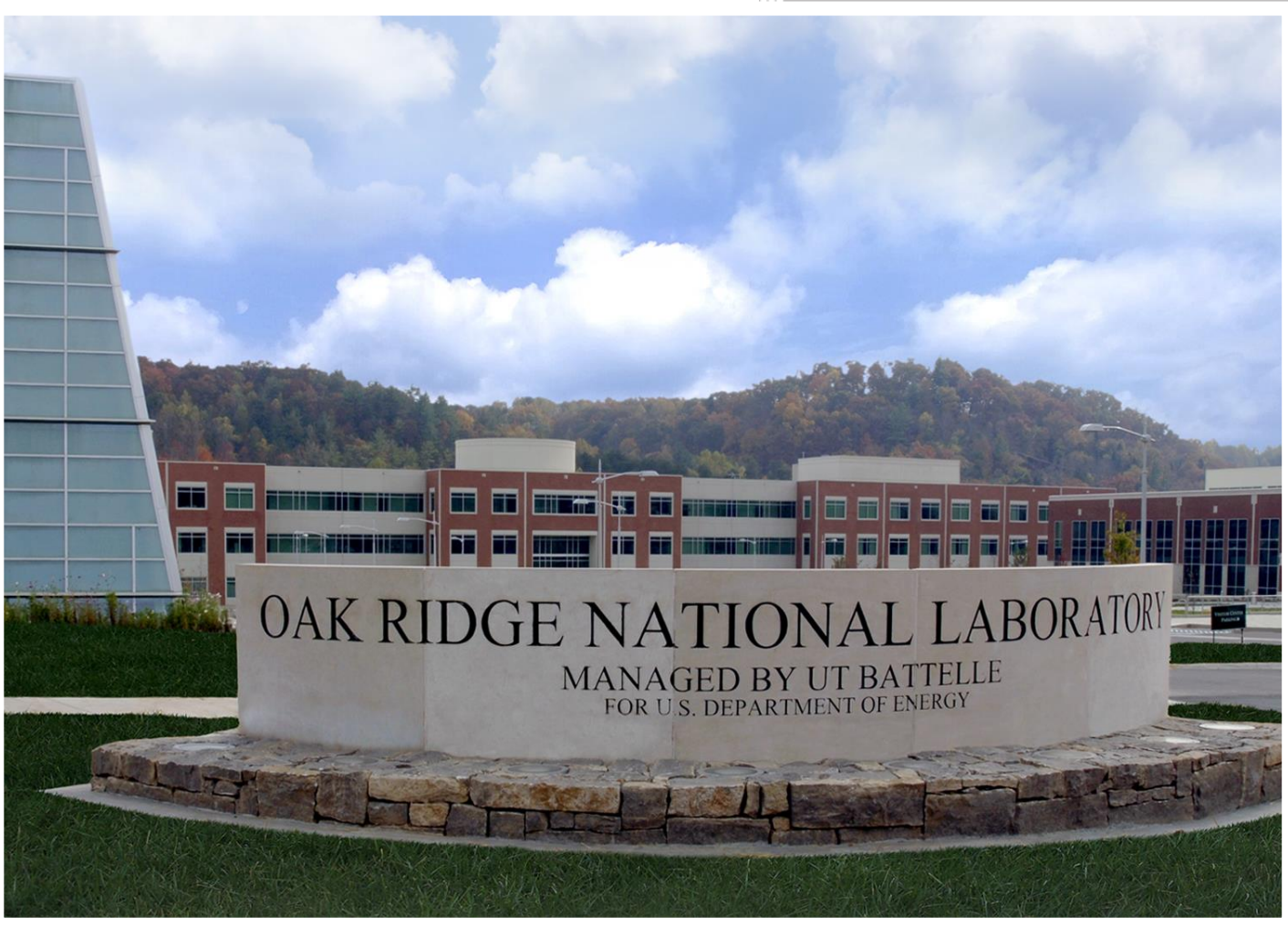

Orlando Rios William Carter Ronald Akers William Morrison January 7, 2016

CRADA FINAL REPORT NFE-14-05319

Approved for Public Release. Distribution is Unlimited. 


\section{DOCUMENT AVAILABILITY}

Reports produced after January 1, 1996, are generally available free via US Department of Energy (DOE) SciTech Connect.

Website http://www.osti.gov/scitech/

Reports produced before January 1, 1996, may be purchased by members of the public from the following source:

National Technical Information Service
5285 Port Royal Road
Springfield, VA 22161
Telephone 703-605-6000 (1-800-553-6847)
TDD 703-487-4639
Fax 703-605-6900
E-mail info@ntis.gov
Website http://www.ntis.gov/help/ordermethods.aspx

Reports are available to DOE employees, DOE contractors, Energy Technology Data Exchange representatives, and International Nuclear Information System representatives from the following source:

Office of Scientific and Technical Information

PO Box 62

Oak Ridge, TN 37831

Telephone 865-576-8401

Fax 865-576-5728

E-mail reports@osti.gov

Website http://www.osti.gov/contact.html

This report was prepared as an account of work sponsored by an agency of the United States Government. Neither the United States Government nor any agency thereof, nor any of their employees, makes any warranty, express or implied, or assumes any legal liability or responsibility for the accuracy, completeness, or usefulness of any information, apparatus, product, or process disclosed, or represents that its use would not infringe privately owned rights. Reference herein to any specific commercial product, process, or service by trade name, trademark, manufacturer, or otherwise, does not necessarily constitute or imply its endorsement, recommendation, or favoring by the United States Government or any agency thereof. The views and opinions of authors expressed herein do not necessarily state or reflect those of the United States Government or any agency thereof. 
Materials Science and Technology Division Advanced Manufacturing Office

\title{
Low-cost Electromagnetic Heating Technology for Polymer Extrusion-based Additive Manufacturing
}

\author{
Authors \\ Orlando Rios-ORNL \\ William Carter-ORNL \\ Adam Morrison-Ajax Tocco \\ Ronald Akers-Ajax Tocco
}

Date Published:

January 7, 2016

\author{
Prepared by \\ OAK RIDGE NATIONAL LABORATORY \\ Oak Ridge, Tennessee 37831-6283 \\ managed by \\ UT-BATTELLE, LLC \\ for the \\ US DEPARTMENT OF ENERGY \\ under contract DE-AC05-00OR22725
}

Approved For Public Release 


\section{CONTENTS}

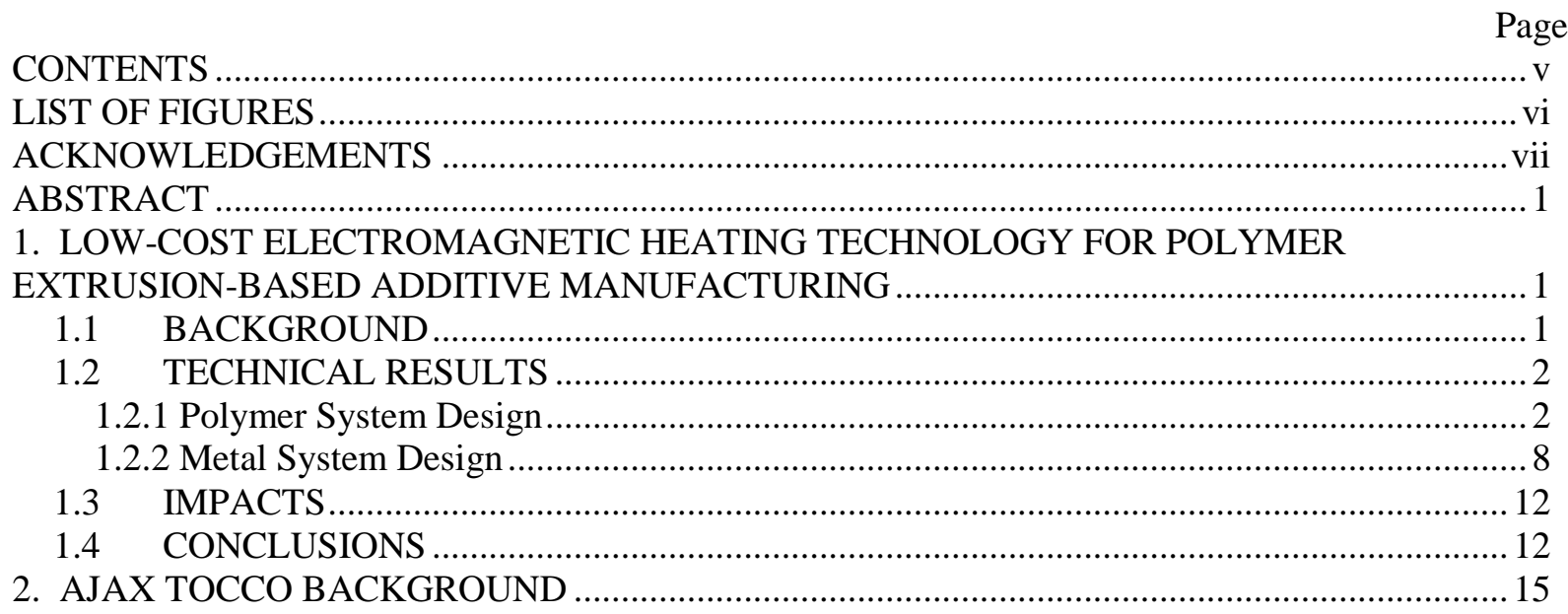




\section{LIST OF FIGURES}

Fig. 1. Prototype induction power supply control box built at ORNL.............................................. 3

Fig. 2. Prototype Low Voltage Induction Power Supply built by Ajax Tocco.................................... 3

Fig. 3. Power supply maximum heating rates in air........................................................................... 4

Fig. 4. Current and voltage (output and control) at low power.......................................................... 4

Fig. 5. Current and voltage (output and control) at medium power................................................ 4

Fig. 6. Current and voltage (output and control) at high power...................................................... 4

Figure 7 - Low voltage 300W induction power supply being tested at Ajax Tocco........................... 5

Fig. 8. Finalized low voltage $300 \mathrm{~W}$ induction power supply with temperature controller................... 5

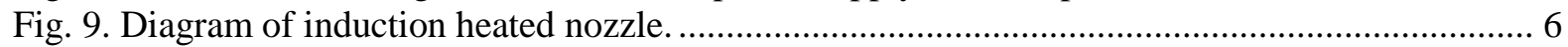

Fig. 10. 300W induction power supply heating curves for constant power showing the maximum heating rates, at higher power levels these rates are significantly faster than those achievable using the

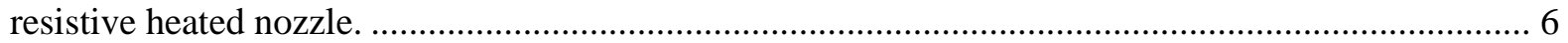

Fig. 11. Current at power supply coil for constant power............................................................. 7

Fig. 12. Steady state control signal from the Yokogawa temperature controller at $180^{\circ} \mathrm{C}$, the system needs more pulses with a greater pulse width to maintain the target temperature at lower power levels.

Fig. 13. Induction heated nozzle attached to PrintSpace workhead.................................................... 8

Fig. 14. Full 300W induction system mounted to PrintSpace Altair. ................................................. 8

Fig. $15.3 \mathrm{~kW}$ direct heating induction system mounted in $80 / 20$ enclosure, the system will be controlled using a Yokogawa temperature controller................................................................... 10

Fig. 16. Controlled heating curve for $300 \mathrm{~W}$ induction heating system, based on this data the system

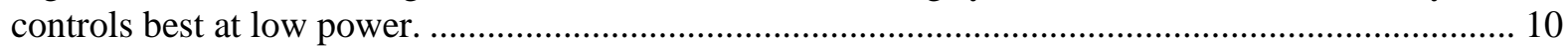

Fig. 17. Building a part with the 300W induction heated nozzle................................................. 11

Fig. 18. Test part built using $300 \mathrm{~W}$ induction heated nozzle at coarse (right), standard (center), and

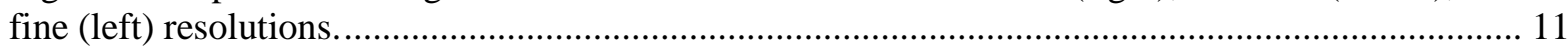

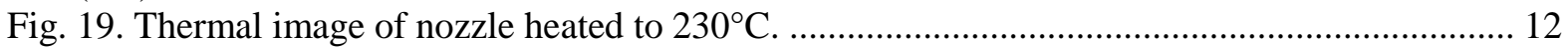

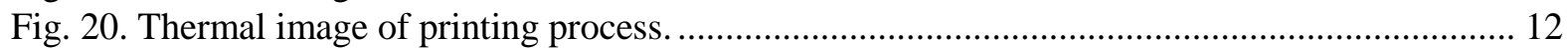




\section{ACKNOWLEDGEMENTS}

This CRADA NFE-14-05319 was conducted as a Technical Collaboration project within the Oak Ridge National Laboratory (ORNL) Manufacturing Demonstration Facility (MDF) sponsored by the US Department of Energy Advanced Manufacturing Office (CPS Agreement Number 24761).

Opportunities for MDF technical collaborations are listed in the announcement "Manufacturing Demonstration Facility Technology Collaborations for US Manufacturers in Advanced Manufacturing and Materials Technologies" posted at http://web.ornl.gov/sci/manufacturing/docs/FBO-ORNL-MDF-2013-2.pdf. The goal of technical collaborations is to engage industry partners to participate in short-term, collaborative projects within the Manufacturing Demonstration Facility (MDF) to assess applicability and of new energy efficient manufacturing technologies. Research sponsored by the U.S. Department of Energy, Office of Energy Efficiency and Renewable Energy, Advanced Manufacturing Office, under contract DE-AC0500OR22725 with UT-Battelle, LLC. 


\begin{abstract}
To improve the flow of materials used in in polymer additive manufacturing, ORNL and Ajax Tocco created an induction system for heating fused deposition modeling (FDM) nozzles used in polymer additive manufacturing. The system is capable of reaching a temperature of $230^{\circ} \mathrm{C}$, a typical nozzle temperature for extruding ABS polymers, in 17 seconds. A prototype system was built at ORNL and sent to Ajax Tocco who analyzed the system and created a finalized power supply. The induction system was mounted to a PrintSpace Altair desktop printer and used to create several test parts similar in quality to those created using a resistive heated nozzle.
\end{abstract}

\title{
1. LOW-COST ELECTROMAGNETIC HEATING TECHNOLOGY FOR POLYMER EXTRUSION-BASED ADDITIVE MANUFACTURING
}

This phase one technical collaboration project (MDF-TC-2014-052) began on January 16, 2015 and was completed on October 31, 2015. The collaboration partner Ajax TOCCO Magnethermic Corporation is a large business. The project partners collaborated to create an induction heating system for fused deposition modeling nozzles, coupled the induction system to a desktop printer and manufactured test parts.

\subsection{BACKGROUND}

Additive manufacturing may be used to quickly and efficiently manufacture complex threedimensional components layer-by-layer, effectively forming complex components. Such additive manufacturing may be accomplished using polymers, alloys, powders, wires, or similar feed stock materials that transition from a liquid or granular state to a cured, solid component. Polymer-based additive manufacturing is presently accomplished by several technologies that rely on feeding polymer materials through a nozzle that is precisely located over a preheated polymer substrate. Parts are manufactured by the deposition of new layers of materials above the previously deposited layers. Polymer extrusion based additive manufacturing systems are among the highest throughput systems and produce the lowest cost components, however these systems lack control in transient start/stop. Intermittent deposition control methods are already available in e-beam, UV cure polymer, and ink jet systems.

Heating of the feed or filler material in the nozzle in additive manufacturing is generally accomplished by direct contact between a polymer feed stock and a heating element, typically a resistively heated metal cylinder at elevated temperatures. There are inherent limitations to this technology that prevent higher deposition rates, out of furnace printing and control of microstructural defects (such as pores). In addition, existing additive manufacturing processes, including polymer extrusion based deposition for additive manufacturing, typically exhibit a thermal lag associated with heating a deposition nozzle. Typical polymer based extrusion systems obtain thermal stability by maintaining a massive resistive heater at a constant temperature resulting in slow response. This makes accurate flow control difficult and prevents the building of advanced structures that require transient deposition rates and frequent interruptions in flow (in a mechanism analogous to image generation in an ink jet printer).

Magneto-thermal conversion is the conversion of electromagnetic energy into thermal energy. In ferromagnetic magnetic materials, a principle mechanism underlying magneto-thermal conversion is 
related to externally induced disturbances in the magnetic structure and how strongly the materials resist these disturbances. The dissipated electromagnetic energy is the product of these two and can be transformed into thermal energy among other forms. Therefore the external field should be sufficient to induce disturbances in the magnetic structure while the magnetic material should provide sufficient resistance to dissipate energy yet not resist so strongly that the external fields cannot induce disturbances. It is therefore desired to match the magnetic response of a material with the correct amplitude and frequency of electromagnetic energy. In soft magnetic materials, there is a minimal energetic barrier to either rotate the moment within a domain, or nucleate a reversed domain and move the resulting domain as opposed to hard magnetic materials that resist such disturbances. The energy product associated with magnetic materials is a function of the coercivity, remnant magnetization and magnetic anisotropy. In general, materials with coercivity $\geq 1000$ Oe can be classified as hard ferromagnets. Soft ferromagnets have lower coercivity, and good soft ferromagnets have coercivity $<1$ Oe. Intermediate materials having a coercivity $>1$ Oe and $<1000$ Oe are useful in applications where a magnetic hysteresis losses are required in applications such as, for example, transformation of electromagnetic energy into thermal energy, also known as magneto-thermal conversion.

\subsection{TECHNICAL RESULTS}

ORNL and Ajax Tocco created an induction system for heating FDM nozzles. The system is capable of reaching a temperature of $230^{\circ} \mathrm{C}$, a typical nozzle temperature for extruding ABS, in 17 seconds. A prototype system was built at ORNL and sent to Ajax Tocco who analyzed it and created a finalized power supply. The induction system was mounted to a PrintSpace Altair desktop printer and used to create several test parts similar in quality to those created using a resistive heated nozzle.

\subsubsection{Polymer System Design}

The prototype power supply was comprised of a control box built at ORNL using off the shelf components housed in a printed box built at the ORNL Manufacturing Demonstration Facility (MDF) (fig. 1) and a supply built by Ajax Tocco (fig. 2). The control box consisted of a $2 \mathrm{~kW}$ power supply connected to a DC motor controller which is controlled by either manual controls or a Yokogawa temperature controller. The motor controller is used to control the output of the box which is fed to the Ajax Tocco supply. This supply takes the Pulse Width Modulation (PWM) output from the control box and turns it into a $30 \mathrm{kHz}$ high frequency induction signal.

The power supply built by Ajax TOCCO is a low voltage induction power supply in a low-cost compact format. The unit is powered by $12 \mathrm{~V}$ DC or $120 \mathrm{~V}$ AC while the output to the coil is maintained below 40 Vrms thereby maximizing electrical safety. Simplicity is designed into the power supply to maximize reliability and minimize cost. The innovative Ajax TOCCO design circumvents many of the advanced design requirements typically associated with induction heating such as resonant frequency seeking or transient crossover detection. The result is a robust yet low-cost platform that can be tuned to the specific power requirements of a wide array of current and future polymer additive manufacturing systems. 


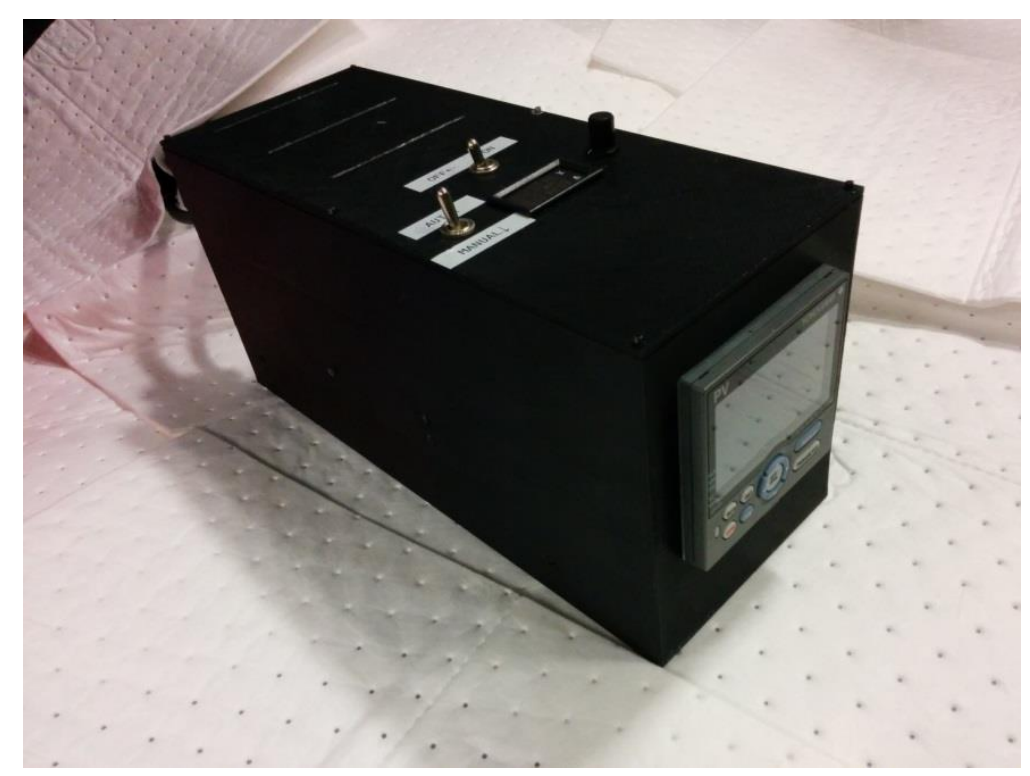

Fig. 1. Prototype induction power supply control box built at ORNL.

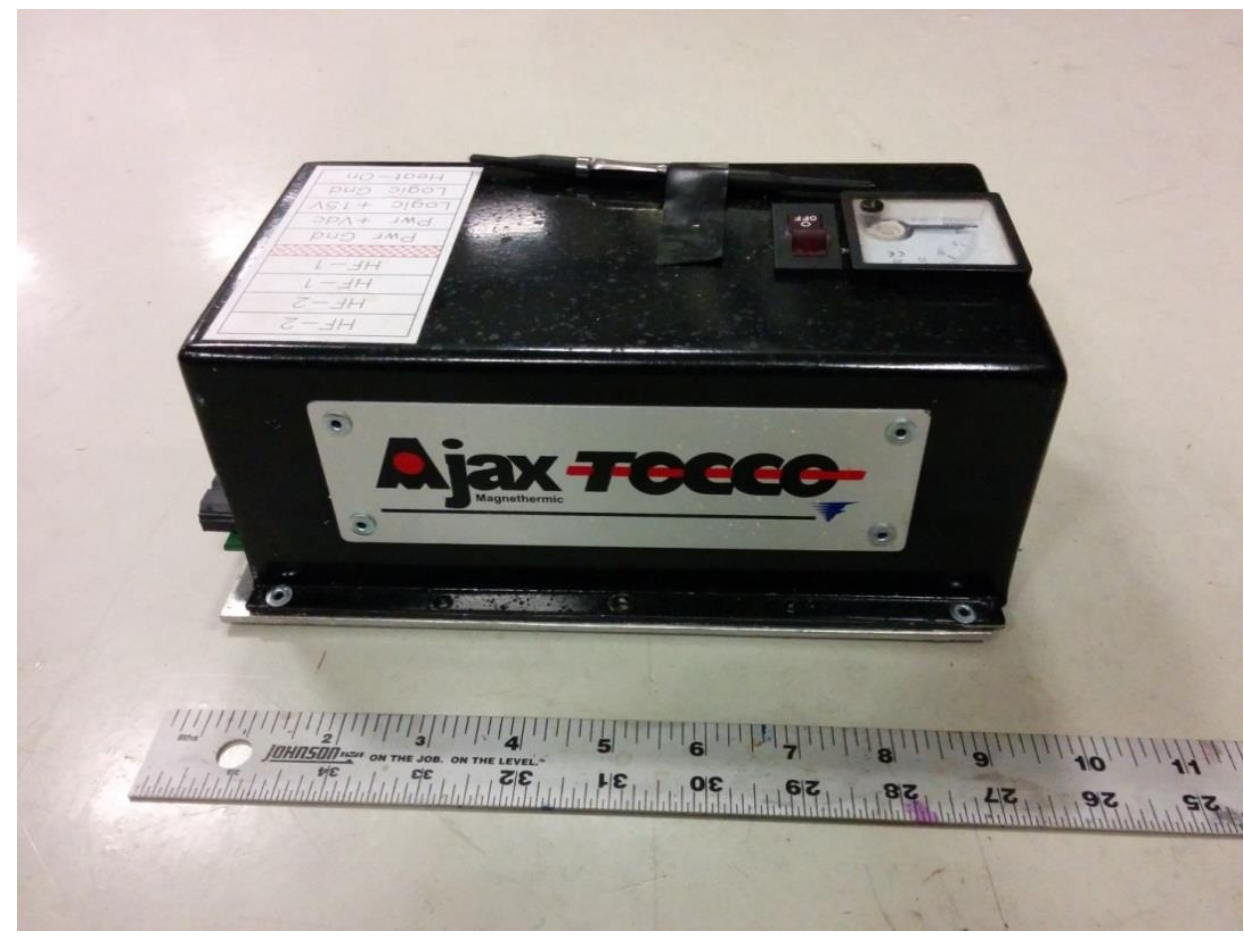

Fig. 2. Prototype Low Voltage Induction Power Supply built by Ajax Tocco.

The control box and power supply were tested at multiple input levels. The current at the coil, input voltage to the supply, and voltage at the coil were monitored, the voltages directly and the current using a Rogowski coil. The power supply behaved as expected and was able to heat a dummy nozzle very quickly (figures 3-6). 

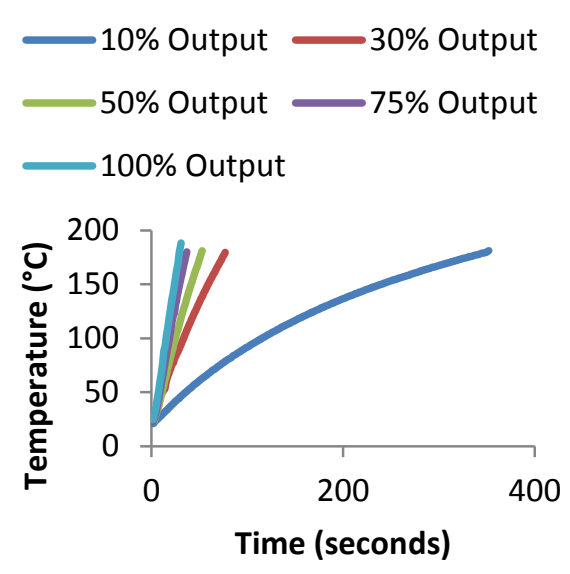

Fig. 3. Power supply maximum heating rates in

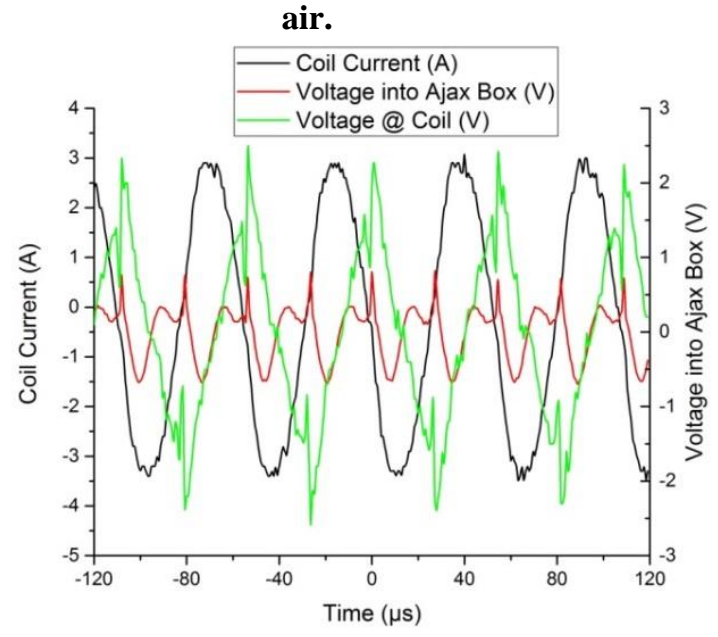

Fig. 4. Current and voltage (output and control) at low power.

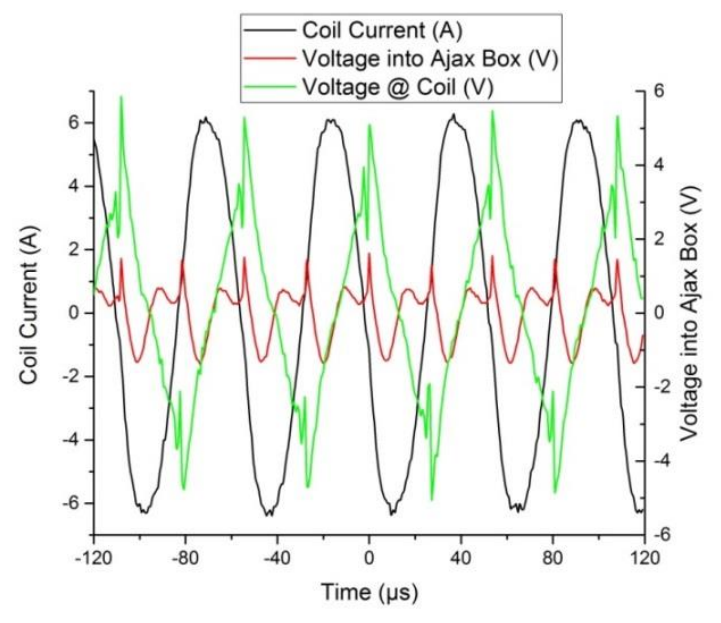

Fig. 5. Current and voltage (output and control) at medium power.

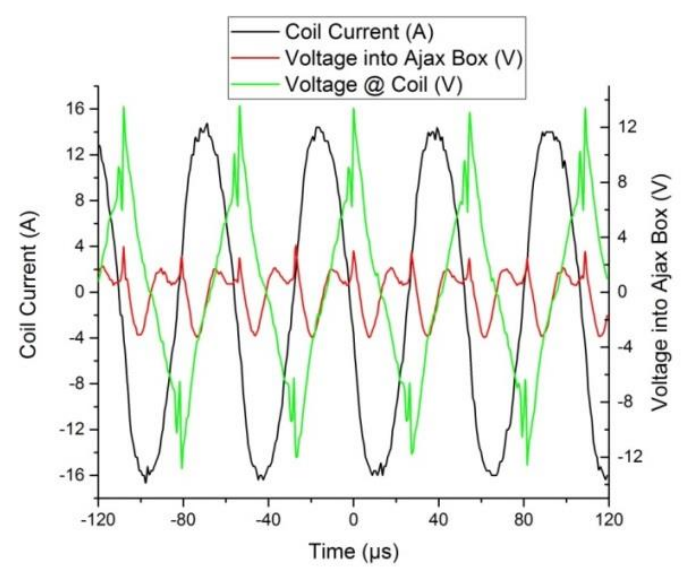

Fig. 6. Current and voltage (output and control) at high power.

The control box was next sent to Ajax Tocco who built a unit combining the controls and the power supply along with inputs for an external temperature control box (figures 7, 8, \&9) The DC input voltage for the induction power supply is supplied by an external $24 \mathrm{~V}$ DC power supply. The induction system powers a coil which is wrapped around the insulated barrel of the printer nozzle. The system is capable of outputting up to $300 \mathrm{~W}$ of power at under $20 \mathrm{~V}$ and a frequency of around $20 \mathrm{kHz}$. 


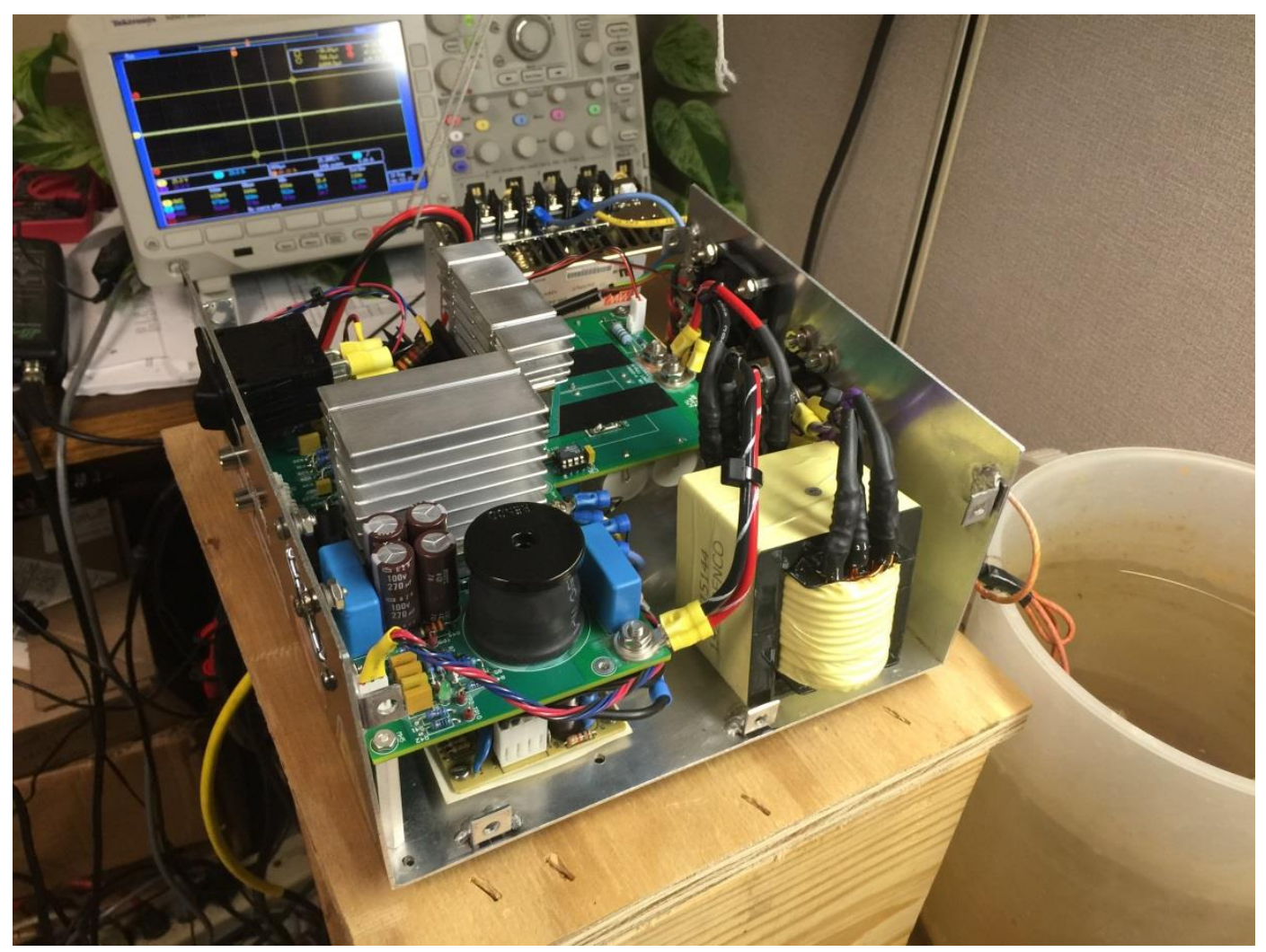

Figure 7 - Low voltage 300W induction power supply being tested at Ajax Tocco

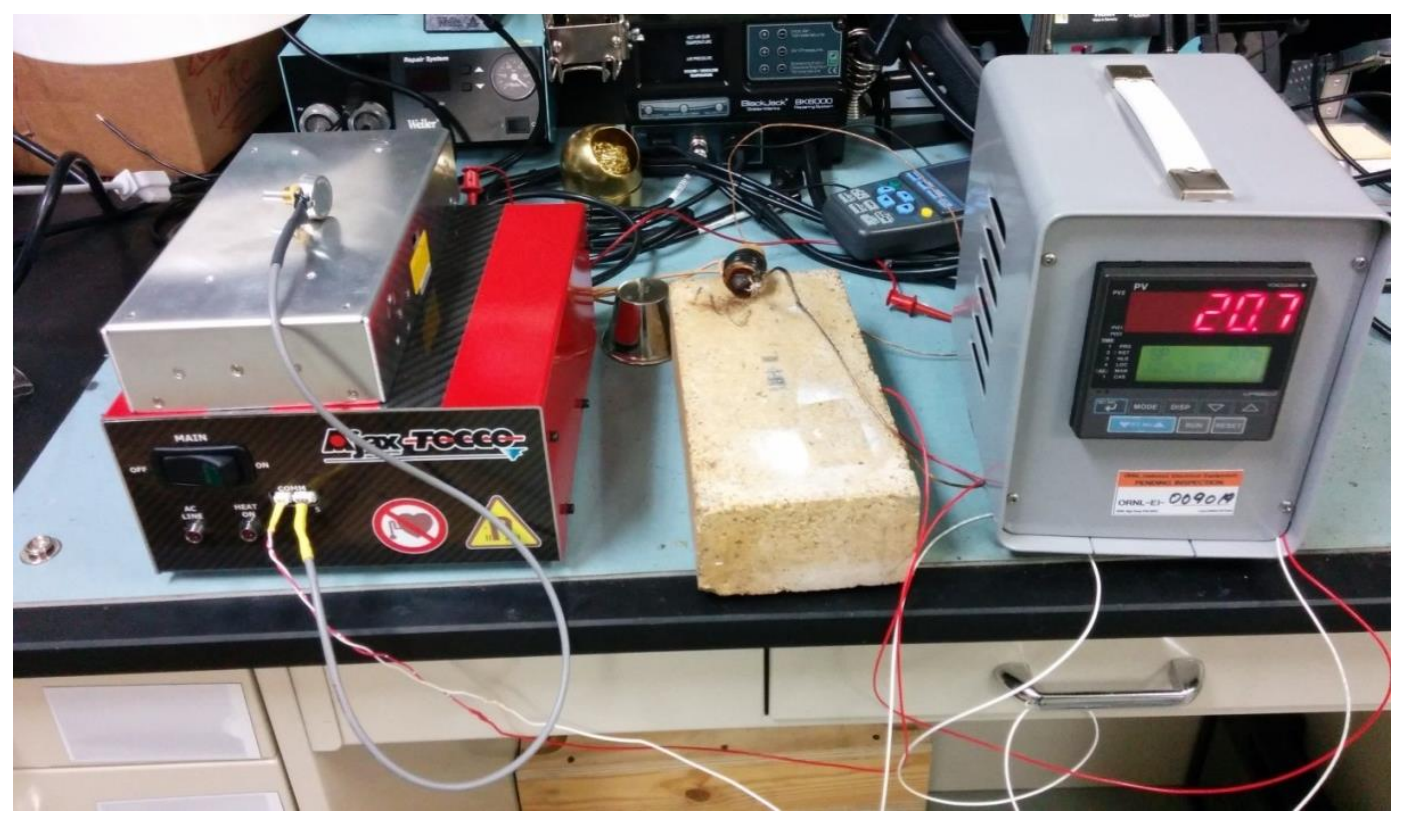

Fig. 8. Finalized low voltage $300 \mathrm{~W}$ induction power supply with temperature controller. 


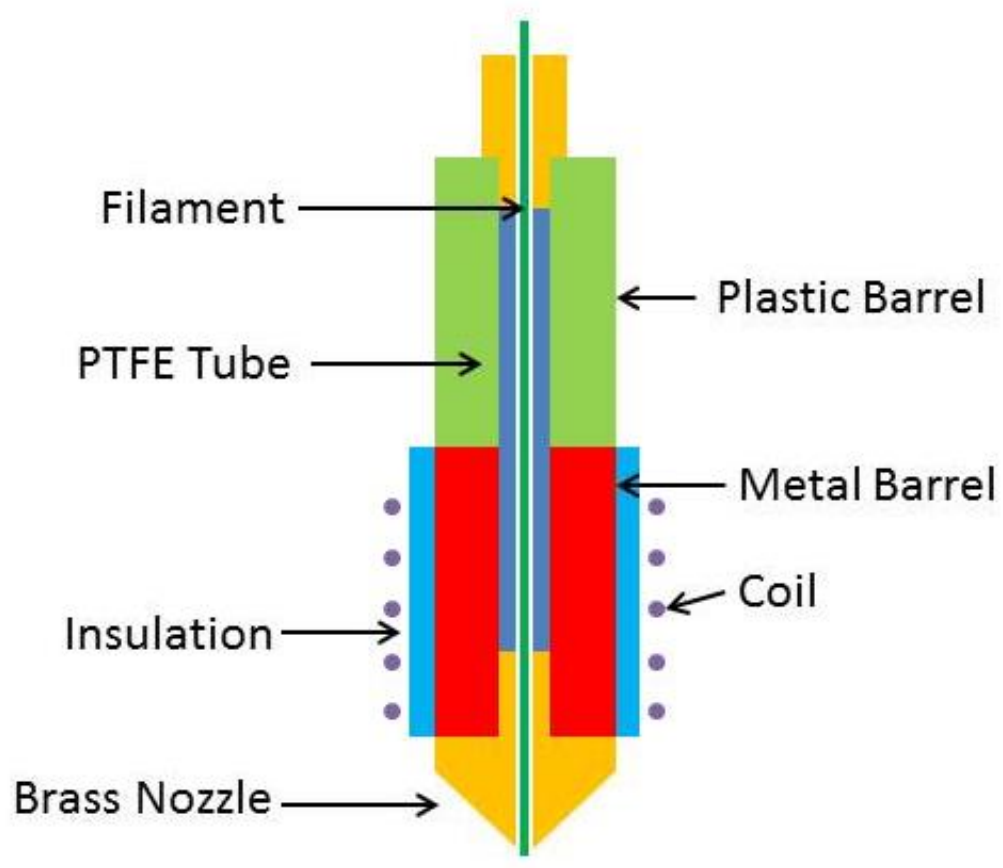

Fig. 9. Diagram of induction heated nozzle.

Due to the relatively high power output of the supply even at its lowest setting (Fig. 10) the temperature controller had to use PWM control as opposed to the analog control used with other induction power supplies (figures $11,12, \& 16$ ).

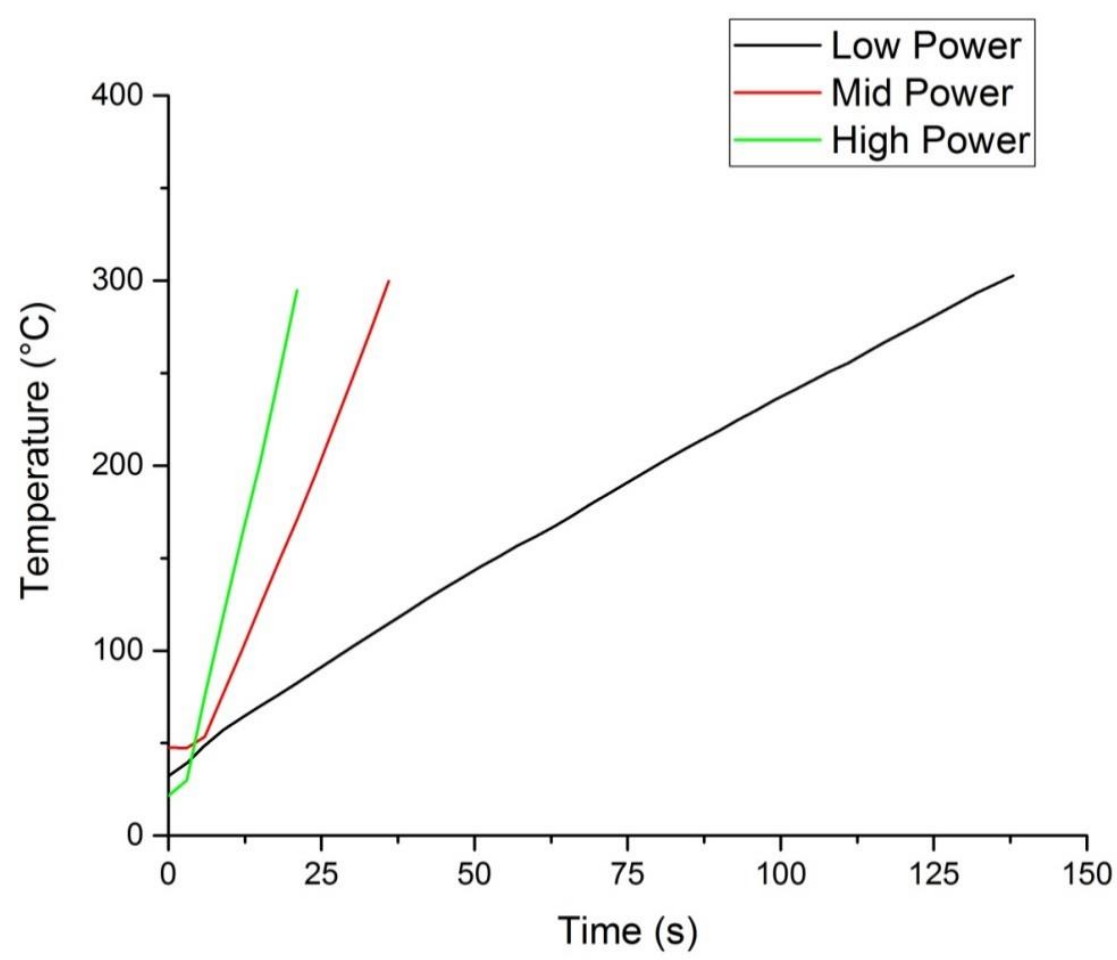

Fig. 10. 300W induction power supply heating curves for constant power showing the maximum heating 
rates, at higher power levels these rates are significantly faster than those achievable using the resistive heated nozzle.

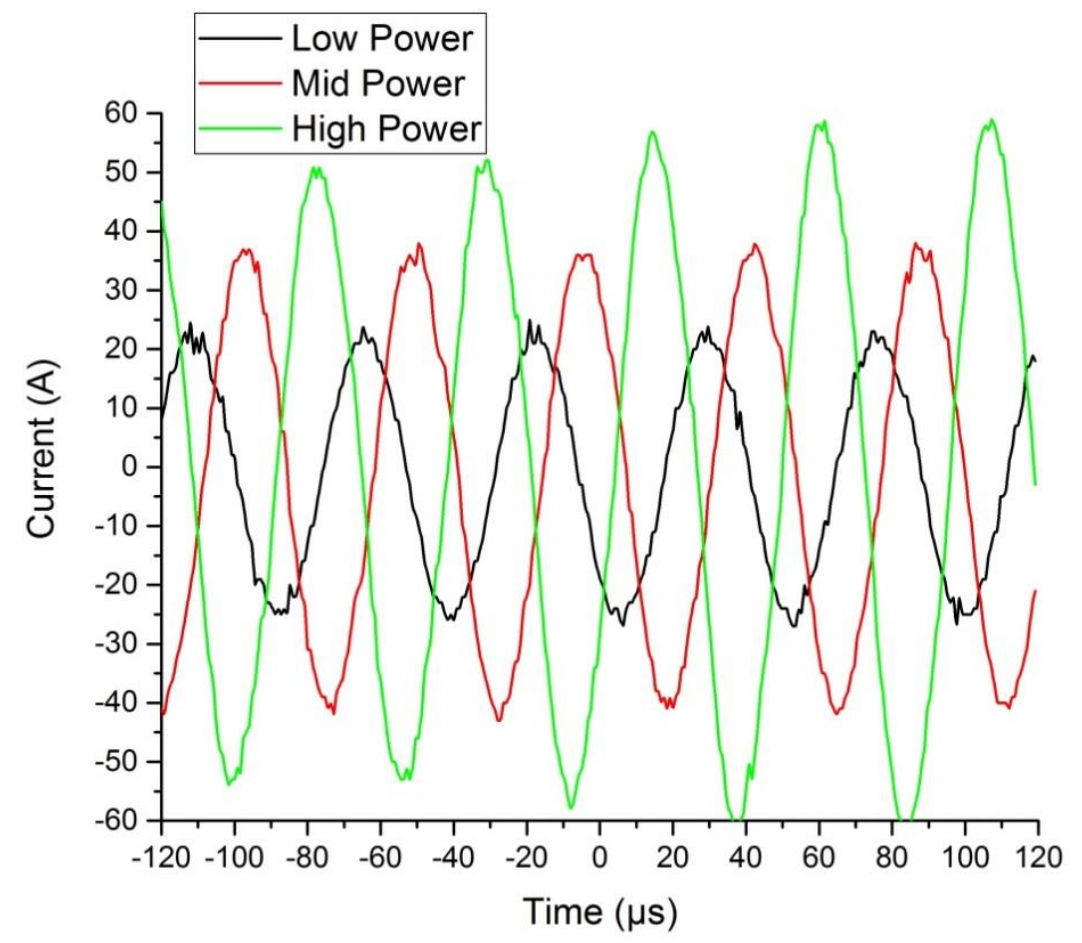

Fig. 11. Current at power supply coil for constant power.

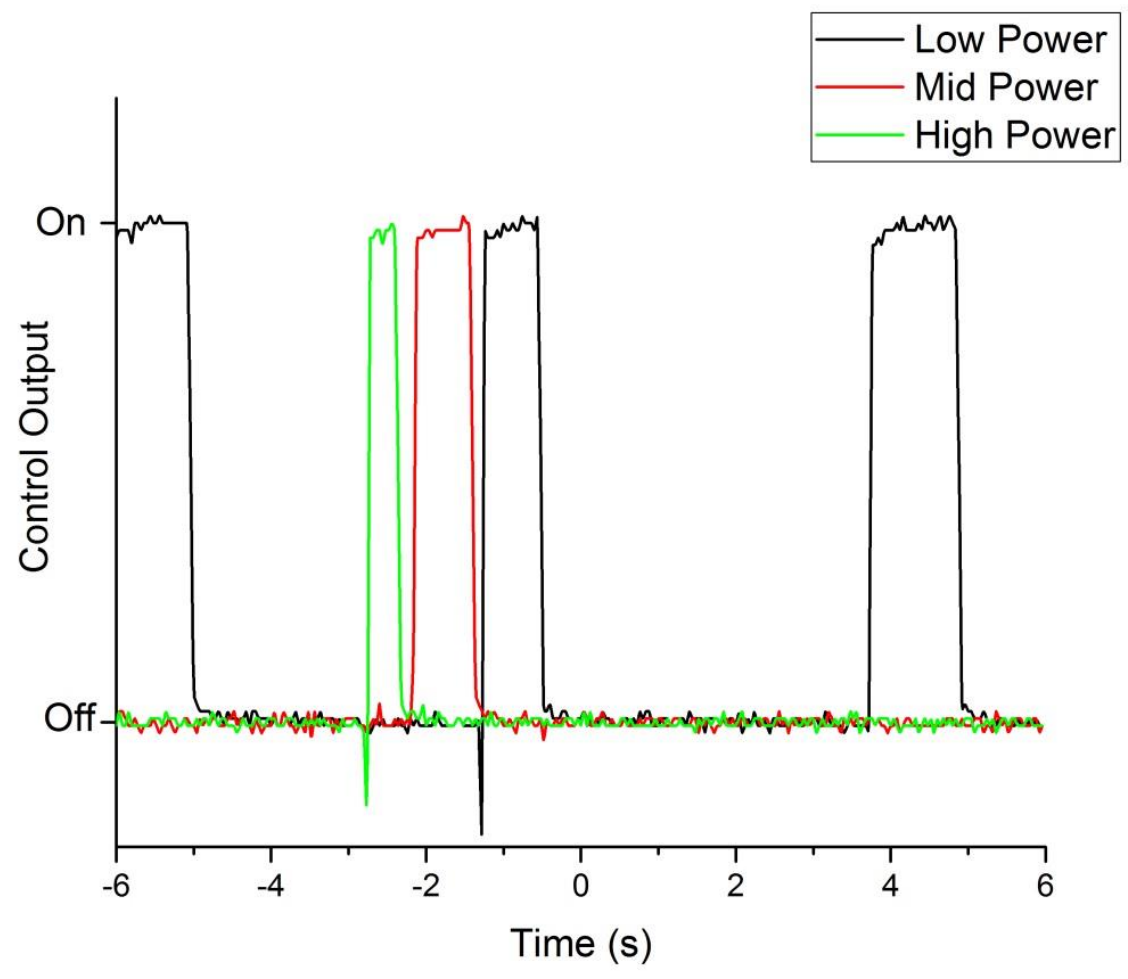


Fig. 12. Steady state control signal from the Yokogawa temperature controller at $180^{\circ} \mathrm{C}$, the system needs more pulses with a greater pulse width to maintain the target temperature at lower power levels.

The heated nozzle was mounted to a modified Bowden hot end from a Rostock printer (Fig. 13). This assembly was then mounted on a PrintSpace Altair delta style fused filament system for testing (Fig.14).

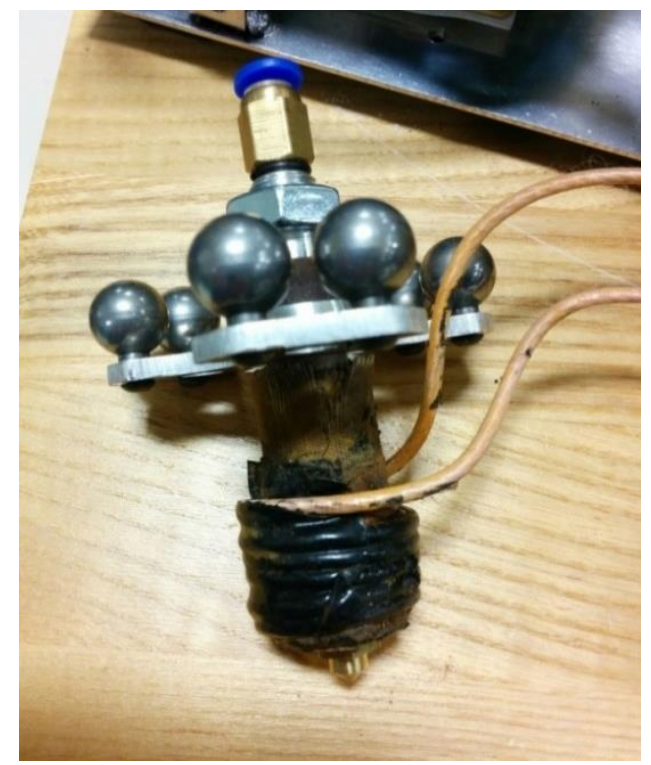

Fig. 13. Induction heated nozzle attached to PrintSpace work head.

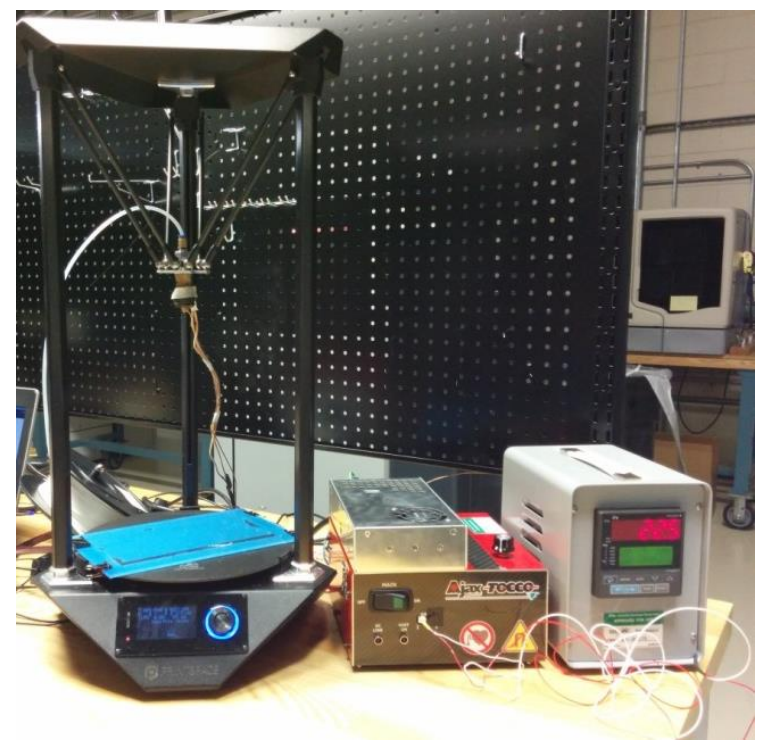

Fig. 14. Full 300W induction system mounted to PrintSpace Altair.

When the first extrusion test was run using the induction heated nozzle the filament melted in the barrel before reaching the brass tip. This caused the barrel to fill with melted filament interfering with extrusion. This problem was solved by putting a short section of $2 \mathrm{~mm}$ ID Teflon tubing inside the barrel reducing the volume that could be filled with melted filament. This problem could be avoided completely by reducing the length of the coil shortening the length of the heated section to just what is necessary in order to melt the filament. In addition the leads for the coil are very short and need to be lengthened in the future. Both of these modifications will require a complete redesign of the coil due to the power supply's strict inductance requirement.

\subsubsection{Metal System Design}

In addition to the polymer system a second system was created by Ajax Tocco for the purpose of directly heating metals for extrusion. This system consists of a $2 \mathrm{~kW}$ power supply and a boron nitride nozzle designed by ORNL. The power supply is powered by a nominal $120 \mathrm{Vac}$ $50 / 60 \mathrm{~Hz}$ single phase source. However it can operate with input voltages as low as $90 \mathrm{Vac}$ and as high as $300 \mathrm{Vac}$. Output transformer ratio changes are required for input voltages that vary more than $10 \%$ above or below the nominal $120 \mathrm{~V}$ rating in order to maintain $2 \mathrm{~kW}$ output levels and to not exceed to maximum inverter current capability of the inverter.

The inverter logic is self-tuning and will lock onto the natural resonant frequency of the load, which is a combination of the installed tuning capacitance and the heating inductor. This maintains 
optimum output power factor for maximum efficiency and also allows the power supply to compensate for minor inductance variances between identically built heating inductors and/or variations in the routing/length of the HF transmission cables.

The power supply has the ability to be configured with internal or external tuning capacitors. Internal capacitors allow for a more portable unit that is totally self-contained, while remote tuning capacitors can be installed into a volume that is less than $10 \%$ of the main power supply cabinet volume facilitating the installation of the induction coil in remote or difficult to access locations. With internal capacitors the inductor hangs right of the front face of the power source. With remote capacitors a small high frequency (HF) cable (1/2 inch outer diameter (OD)) is used to transmit low level inverter current to a remote capacitor bank (up to $25 \mathrm{ft}$ away) with minimal power losses in the HF cable. The heating inductor is mounted directly to the remote tuning capacitor bank.

Depending on the output transformer arrangement and tuning capacitor voltage capability the power supply can produce output voltages between 40 and $400 \mathrm{Vrms}$ at $50 \mathrm{kHz}$ to satisfy a wide range of heating inductor and application requirements. For the metal additive manufacturing application the coil voltage ranges between $40-60 \mathrm{Vrms}$ at $42 \mathrm{kHz}$.

The power supply has the ability to receive a remote start command via a normally open contact/solid state relay to turn the heating on and off from a remote source. The power source also has the ability to receive an analog input voltage signal from a remote source to proportionately vary the output voltage pulse width of the power supply to vary the average power delivered to the load depending on application requirements. These features provide the user to both turn the heat on and off as well as vary the heating intensity from $2 \%$ to $100 \%$ pulse width.

The heating inductor is a helical wound round solenoid type inductor with an even pitch of 4 turns in $1 "$ length. The inner diameter (ID) of the inductor is 0.75 inches. The conductor is $3 / 16$ " OD oxygen free copper tubing that can be actively cooled by either water/industrial coolant or compressed gasses such as ambient air, argon, nitrogen, etc.

Within the ID of the inductor is a boron nitride cylinder (nozzle) with a bore of approximately $1 / 2$ " and an orifice at the base of approximately $1 / 32 "$. A rod of material, slightly smaller in OD than the ID of the boron nitride cylinder, is inserted into the bore. Another rod made from boron nitride is placed on top of the material and used to apply even pressure to the alloy rod as it is heated and subsequently melted allowing it to be accurately deposited from the small orifice at the end of the boron nitride cylinder. The melted alloy can be deposited and solidified in specific patterns to create almost limitless geometries in a process commonly referred to as additive manufacturing.

The ID and length of the nozzle can be changed to accommodate a wide variety of alloy geometries, sizes and weights determined by the rate at which the alloy needs to be deposited for a specific manufacturing application. The power of the induction heater can be scaled up or down as can the operating frequency depending on the amount, resistivity, magnetic permeability, specific heat, and melting temperature of the material and the rate at which the material has to be heated.

Boron nitride is a preferred material for this application in that it is stable at temperatures over $2000^{\circ} \mathrm{F}$ and is resistant to wetting by most alloys. It is easily machinable allowing it to be cut into unique shapes that may simplify the installation of the nozzle.

This system was mounted in an 80/20 enclosure for testing purposes. Once the system is tested it can be mounted to the BAAM blue gantry system to build test parts (Fig. 14) in phase 2. 

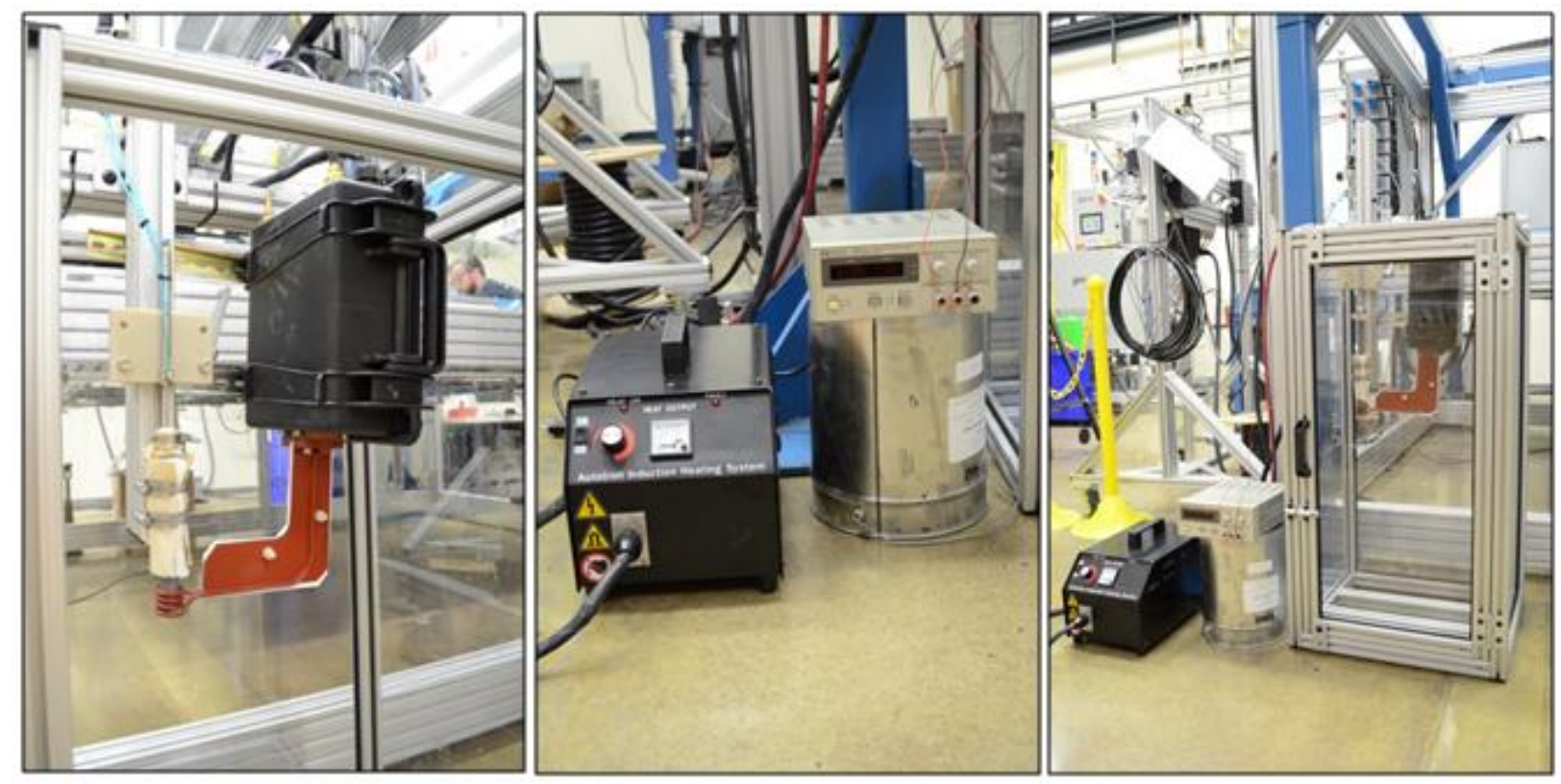

Fig. 15. 3kW direct heating induction system mounted in $80 / 20$ enclosure, the system will be controlled using a Yokogawa temperature controller.

\subsubsection{Results}

The power supply is able to heat the nozzle to $180^{\circ} \mathrm{C}$, a common temperature for polylactic acid (PLA) extrusion, in 13 seconds, and is able to heat the nozzle to $230^{\circ} \mathrm{C}$, a common temperature for acrylonitrile butadiene styrene (ABS) extrusion, in 17 seconds. In comparison, the Nova hot end normally used by the PrintSpace Altair requires 52 seconds to heat to $180^{\circ} \mathrm{C}$ (Fig. 16).

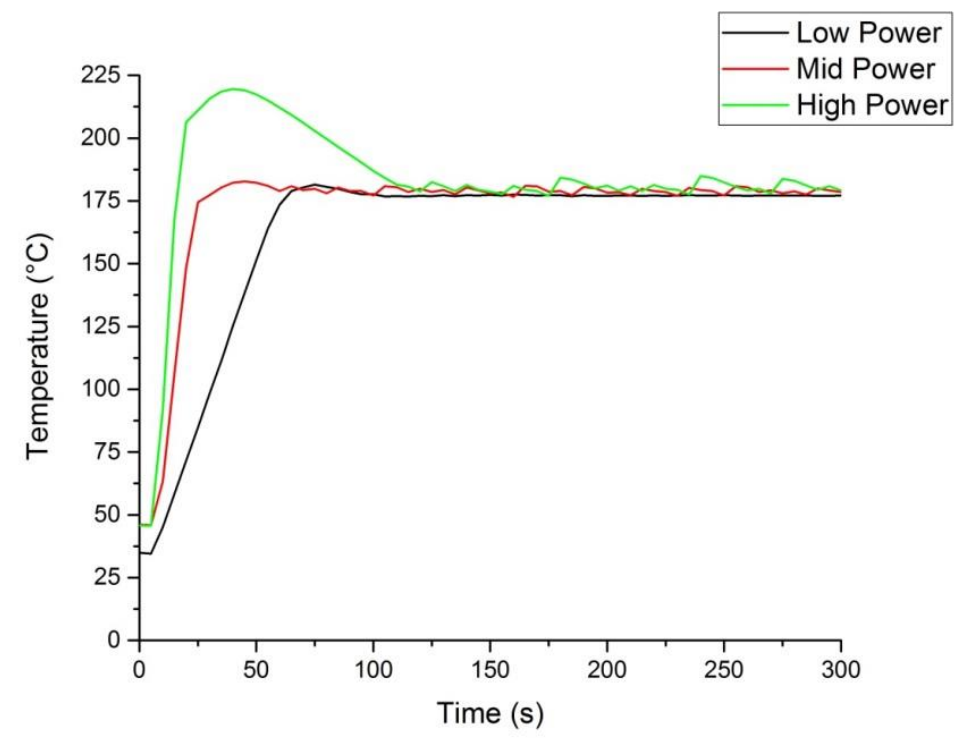

Fig. 16. Controlled heating curve for $300 \mathrm{~W}$ induction heating system, based on this data the system. controls best at low power. 
Test parts were created using ABS with a nozzle temperature of $230^{\circ} \mathrm{C}$ and a bed temperature of $100^{\circ} \mathrm{C}$ (figures $17 \& 18$ ). The parts were printed using a $0.7 \mathrm{~mm}$ nozzle and a glass substrate without a raft. The nozzle performed as expected producing parts similar in quality to those produced using the resistive heated nozzle. Thermal images were taken of the heated nozzle and the printing process (figures $19 \& 20$ ).

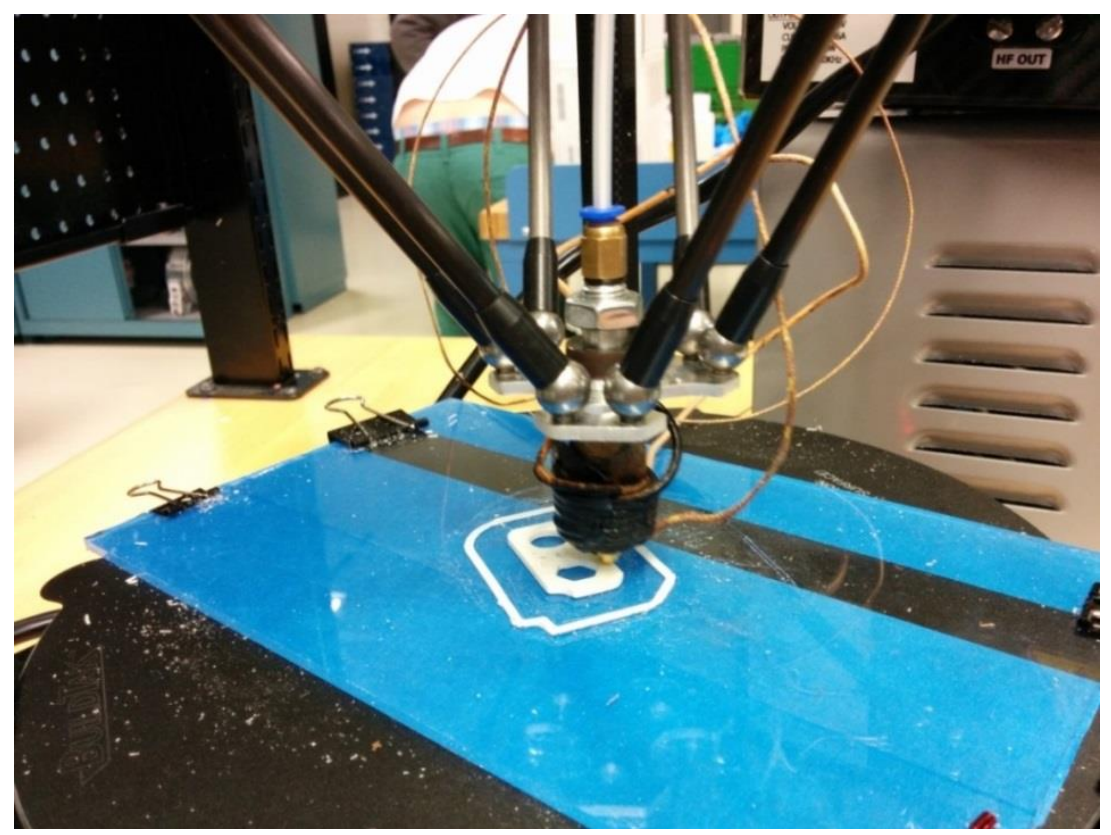

Fig. 17. Building a part with the $300 \mathrm{~W}$ induction heated nozzle.

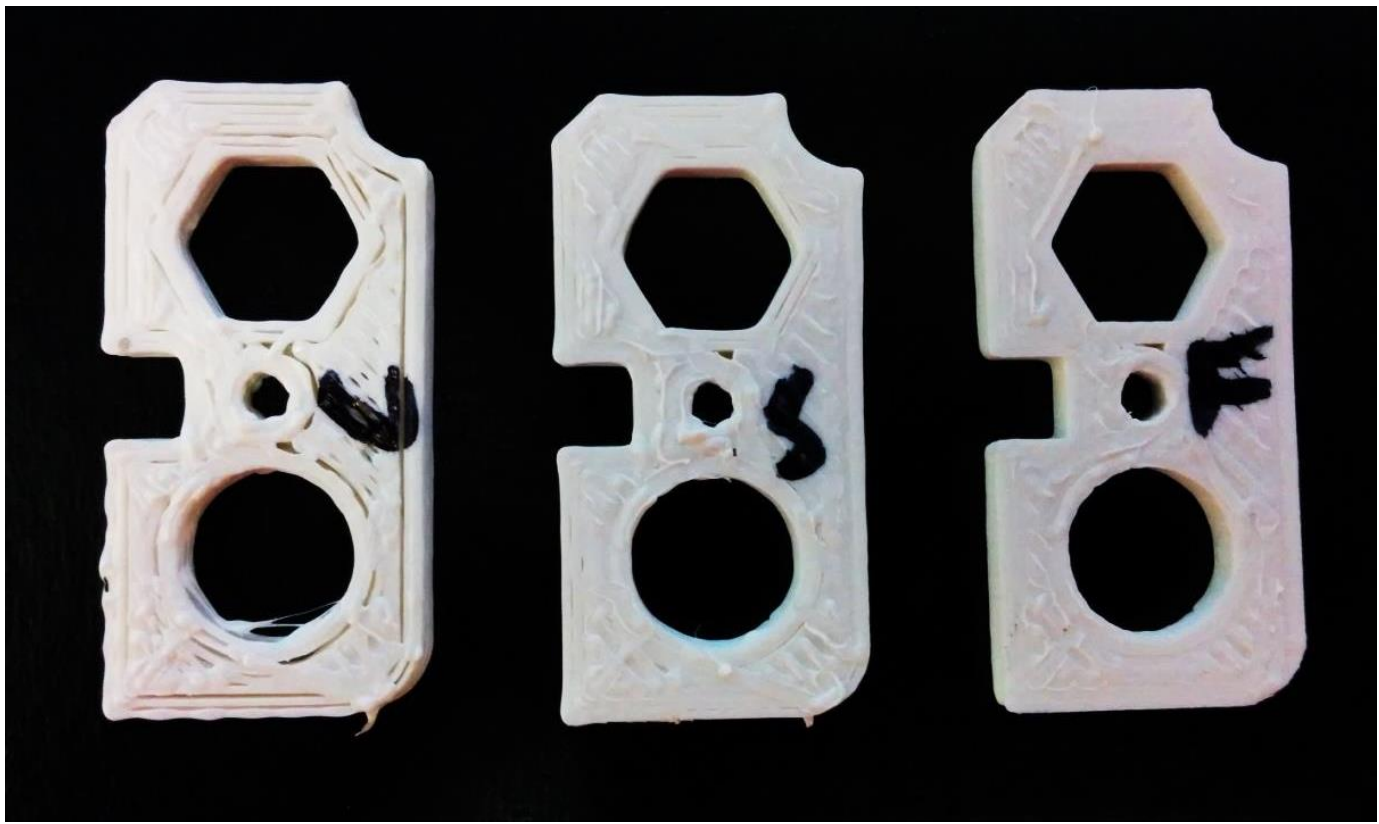

Fig. 18. Test part built using $300 \mathrm{~W}$ induction heated nozzle at coarse (right), standard (center), and fine (left) resolutions. 


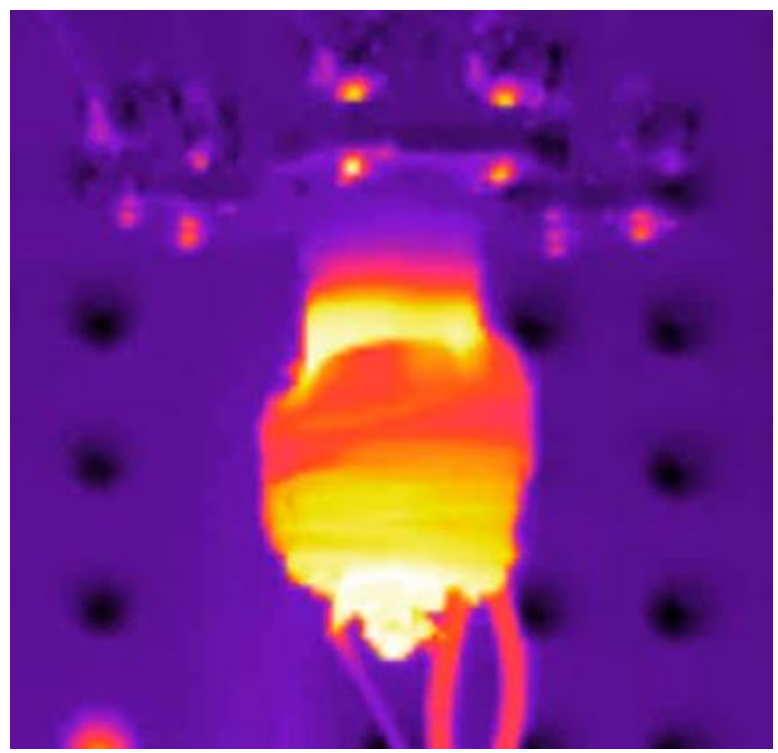

Fig. 19. Thermal image of nozzle heated to $230{ }^{\circ} \mathrm{C}$.

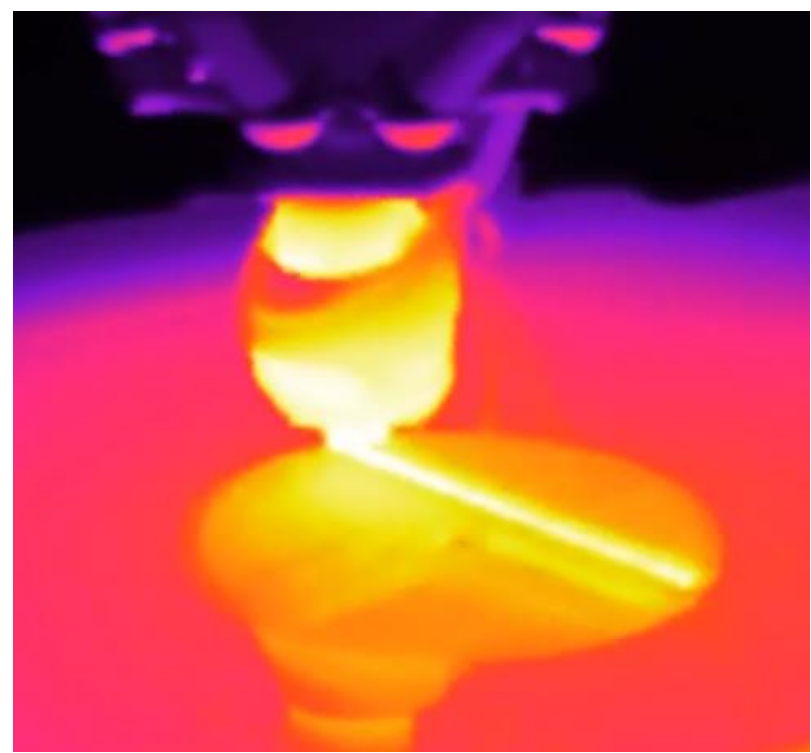

Fig. 20. Thermal image of printing process.

\subsection{IMPACTS}

Resistive heating of thermoplastic materials in FDM additive manufacturing is energy intensive and inhibits precise control of the deposited material. This collaboration between ORNL and Ajax TOCCO evaluated a commercial prototype low-cost induction power supply and induction coil system for operation with the FDM technology. ORNL assisted in the development and testing of control systems for additive manufacturing. This project demonstrated an induction heating technology that can reduce the power consumption of additive manufacturing and produce part higher quality. Ajax TOCCO is considering this product line as a commercial entry-point into the additive manufacturing market. A parallel project extended this technology beyond heating the FDM nozzle to directly coupling with certain materials, such as metals, for instantaneous heating of the extruded material. The largest impact of this technology will be on large scale and high temperature systems which require higher amounts of energy to reach the proper temperatures.

\subsection{CONCLUSIONS}

An induction heated nozzle was created for a fused filament printing system. This nozzle is capable of reaching the temperatures required for deposition faster than the resistively heated nozzle currently in use on fused filament systems, without affecting the quality of the build. This reduction in heating time could lead to less downtime when building multiple parts in succession thus increasing throughput and reducing costs. In addition this system is capable of reaching higher temperatures than the resistively heated nozzle meaning that it could be used for a wider variety of materials including metals.

If approved, phase 2 experiments will demonstrate the wide range of materials the induction heated nozzles are capable of including but not limited to metal slugs, metal wire, and composite filaments. This wider range of materials will allow more flexibility than is currently possibly with small scale systems. The lessons learned while working with this system will be used to help improve the large scale induction system being designed and built for Big Area Additive Manufacturing (BAAM). The metal extrusion system will be mounted to BAAM for small scale testing and a large 
scale version will be developed using the knowledge gained from the small scale experiments.

Potential workflow for phase two of the project:

1. Integration of small power supply with PrintSpace controller.

The PrintSpace Altair has the ability to control an external heater with the use of a solid state relay. We will integrate the induction heating system eliminating the need for an external temperature controller like the Yokogawa system currently in use.

2. Integration of nozzle onto BAAM for demonstration.

We will integrate the nozzle and plunger system along with the small induction heating system into a small scale additive manufacturing system. The barrel of the extrusion apparatus is expected to be below 500C and can be brought down to below 100C with alumina based felt insulation. Although the nozzle is designed, the apparatus to drive the plunger in a controlled manner has not been developed. The force needed to push the plunger is under 10lbs.

3. Casting of 100lbs of Al-Ce cylinders that are compatible with the direct write nozzle. We will cast 0.460 " outer diameter rods that are between 5 and 6 inches long of two Al-Ce alloy compositions. Although the cost of the alloy is under $4 \$ / \mathrm{lb}$, making a small production run requires the manufacturing of new molds and a specialized small batch melt. This elevates the material cost to $50 \$ / \mathrm{lb}$. The future casting of large pre-charges or other formats such as extruded material is expected to significantly reduce the cost of feedstock. We have already produced $\mathrm{Al}$-wire feedstock that is compatible with AM.

4. Evaluate materials in order to determine which is the best fit for additive manufacturing. We will perform tests to determine which material is best suited for additive manufacturing. These tests will look at how well the material works with the deposition system, how much power is required to heat the material to the point where it can be extruded, physical properties of the material, how well the material responds to deposition, and the lamination strength of the deposited material.

5. Print small scale demonstration parts using the small scale nozzle on BAAM.

Once a material has been chosen the small scale system will be used to print parts that fully demonstrate the system's capabilities.

6. Develop large scale system.

We will use the knowledge gained by evaluating materials and demonstrating the small scale system on BAAM to develop a large scale system. 


\section{AJAX TOCCO BACKGROUND}

Ajax TOCCO Magnethermic has worldwide operations in nine countries. In North America, they have manufacturing facilities in two major locations as well as eight regional service centers. Ajax TOCCO is one of the few induction equipment manufacturers that maintains a full-time research and development program. They design and build all of their power supplies and as a result, are able to supply their customers with the latest technology available. Their 600 domestic and international employees give us the ability to handle large orders or volume increases while maintaining their commitment to quality, service and delivery.

Ajax TOCCO is committed to quality in the design, manufacturing, building and support of their equipment. They received their ISO 9001 certification February 20, 1997. Feedback from their customers is used to improve their equipment and product lines.

Ajax Tocco Magnethermic is dedicated to being the World Leader in Induction Melting and Heating Equipment and Associated Services through continuous improvement efforts and constantly "Raising the Bar" on the performance level of all aspects of the business.

Ajax TOCCO offers an extensive computerized inventory of factory certified replacement parts for their induction heating and melting equipment to assure quick turnaround. They also offer replacement parts for all other makes of induction equipment. Their commitment to customer support means Ajax TOCCO is available to handle emergencies any time of the day, any day of the week.

Ajax TOCCO has the engineering staff, materials sourcing, manufacturing capacity, test facilities, floor space, startup service and technical support to provide you with timely delivery. They have full system testing and a metallurgical lab both in their Boaz, Alabama facility and their Warren, Ohio facility.

Ajax TOCCO provides a wide variety of schools for customers since the early 1970's. These include regularly scheduled formal schools at either of their plants in Warren Ohio or Boaz, Alabama or they can arrange for formal or informal instruction at your facility. Training of your personnel usually begins with equipment runoff and startup; formal maintenance training is usually scheduled sometime after the equipment has been in operation. 